\title{
REPROdUÇão humana ASSISTIDA: A RESOLUÇão 2013/13 do CONSELHO Federal de Medicina (CFM)
}

\author{
Assisted human reproduction: the resolution 2013/13 of Federal Council of \\ Medicine
}

\section{Leandro Reinaldo da Cunha}

Doutorando em Direito pela Pontifícia Universidade Católica de São Paulo PUC/SP e Mestre em Direito pela Universidade Metropolitana de Santos - UNIMES. Pesquisador Científico. Professor de Pós-Graduação e Graduação da Universidade Nove Julho. Professor da Universidade Metodista de São Paulo. E-mail: leandrocunha@aasp.org.br.

\section{Terezinha de Oliveira Domingos}

Doutora e Mestre em Direito pela Pontifícia Universidade Católica de São Paulo - PUC/SP. Pesquisadora Científica de Grupos de Pesquisa certificados no CNPq. Coordenadora, Professora de Graduação e de Pós-Graduação, Professora orientadora de Pesquisa Científica da Universidade Nove de Julho - UNINOVE. E-mail: terezinhaod@hotmail.com.

RECEBIDO EM: 04.03.2013

APROVADO EM: 20.06.2013

\section{Resumo}

A reprodução humana assistida é uma forma de reprodução que busca permitir que pessoas que não reúnem condição de procriar pelas vias naturais possam vir a experimentar a experiência da paternidade. A questão é que apesar de tratar-se de uma realidade científica desde o final da década de 1970 e início da década de 1980, é tema que não encontra a devida atenção do ordenamento jurídico nacional, o que permite o surgimento de inúmeros questionamentos, e a tomada de resoluções de entidade de classes como parâmetro para a compreensão da questão. Abordaremos neste artigo a reprodução humana assistida considerando a recente Resolução 2013/13 do Conselho Federal de Medicina (CFM).

Palavras-chave: Reprodução humana assistida. Paternidade. Biodireito. DignidaDE DA PESSOA HUMANA. 


\begin{abstract}
The assisted human reproduction is a form of reproduction that seeks to allow people who do not meet condition of breeding by natural means may come to experiment the experience of parenthood. The point is that even though it is a scientific reality since the late 1970 's and early 1980 's, it is a theme that has no proper attention from the national legal system, which allows the emergence of numerous questions, and making entity class's resolutions as a parameter for understanding the question. Discuss this article assisted human reproduction considering the recent Resolution 2013/13 of Federal Council of Medicine (CFM).
\end{abstract}

Keywords: Assisted human reproduction. Parenthood. Dignity of the Person hUMAN.

Sumário: 1. Paternidade e reprodução assistida. 1.1. Requisitos pessoais para a participação em processo de reprodução assistida. 1.2. Sexualidade e reprodução assistida. 1.3. Das responsabilidades dos estabelecimentos que efetivam as técnicas de reprodução assistida. 2. Da doação de matérial genético. 2.1. Do destino do material genético não utilizado. 3. Gestação em substituição. 3.1. Do contrato de gestação em substituição. 3.1.1 Da licitude do objeto do contrato. 3.2. Da eficácia do contrato. Conclusão. Referências.

\title{
INTRODUÇÃO
}

A realidade da sociedade atual é bastante distinta daquela vivenciada em outros tempos, ante as constantes mudanças pelas quais o mundo passa neste peculiar período da humanidade em que inovações do mundo científico contrastam com ramos da coletividade que se mostram absolutamente moralistas e conservadores, num conflito que muitas vezes ganha contornos surreais. De um lado se colocam a realidade do mundo virtual, os desafios ambientais vinculados a manutenção da espécie humana e relacionados a sustentabilidade e os inúmeros avanços quanto a saúde ombreiam com preconceitos das mais variadas espécies, como a discriminação por conta de cor de pele, orientação sexual ou classe social.

Estas mudanças na realidade das sociedades devem ser objeto de atenção por parte do legislador, a fim de garantir uma legislação vinculada com o seu tempo e em consonância com a realidade da população a ela sujeita, sob pena de manifesta afronta ao exercício pleno da atividade jurisdicional do Estado.

O simples fato do decorrer do tempo entre a elaboração do texto do Código Civil e os dias atuais por si só já seria suficiente para que surgissem questionamentos 
ante a série de mudanças sociais vividas neste período, considerando-se que quando de sua edição não existiam inovações extraordinárias que hoje fazem parte do cotidiano da população, como o Facebook e o YouTube, para ficar apenas em algumas evoluções virtuais.

Ocorre, contudo, que algumas evoluções da ciência que já eram realidade consolidada quando do início da vigência do Código Civil foram ignoradas de forma absurda ou então não se revestiram da devida relevância, sendo relegadas pelo legislador, dando azo ao surgimento de um grande número de lacunas normativas inadmissíveis, nas mais diversas esferas.

No que concerne ao biodireito uma das lacunas mais clamorosas que se pode constatar esta relacionada à reprodução assistida ou à inseminação artificial, tema que ganhou atenção de forma parca em apenas em 3 incisos do art. 1597 do Código Civil, que se presta a tratar da presunção de paternidade dos filhos nascidos na constância do casamento.

Considerando a relevância do tema e a leniência do Poder Legislativo, atualmente tem-se socorrido em parâmetros não legislativos para apreciar as questões vinculadas à reprodução assistida, como é o caso da Resolução 2.013/13 do Conselho Federal de Medicina (CFM), de 16 de abril de 2013, que revogando a Resolução CFM n ${ }^{\circ} 1.957 / 10$, fixa as normas de fundo deontológico a ser seguido pelos médicos nesta seara, ainda que desprovida de eficácia erga omnes.

$\mathrm{O}$ referido dispositivo colaciona um conjunto de diretrizes às quais os profissionais da área médica estão atrelados na condição de sua atividade profissional e, mesmo com esta eficácia restrita, o consignado no corpo da Resolução 2.013/13 do Conselho Federal de Medicina (CFM) tem sido considerado como o padrão ético a ser seguido pela ciência médica no que concerne à reprodução assistida.

Valendo-se do método dedutivo, a presente análise tem por premissas elementar a realidade da sociedade e a pronta necessidade da fixação de um conjunto normativo com o objetivo de solucionar as inúmeras incertezas atreladas ao tema com o fulcro de equacionar sérias celeumas que se estabelecem em casos de reprodução assistida.

\section{Paternidade e reprodução assistida}

O legislador pátrio, conforme já aventado, praticamente ignora a existência da reprodução humana assistida no corpo do ordenamento jurídico vigente, apenas tratando o tema de forma absolutamente superficial ao tratar da presunção de filiação na constância do casamento.

O interesse pela paternidade é característica inerente à condição humana de perpetuação da espécie, podendo-se pugnar pela existência de um "direito à procriação do ser humano" ou um direito subjetivo de procriar, numa projeção da 
personalidade humana, decorrente do direito da personalidade ${ }^{431}$, sendo certo que nem sempre a capacidade de procriar se faz presente, havendo a necessidade da intervenção científica a fim de se atingir este objetivo.

No que tange a paternidade, tem-se que, ordinariamente, esta será apreciada na modalidade matrimonial, segundo a qual existindo casamento vigente há a presunção de que a mãe é aquela que deu a luz à criança, enquanto o pai seria o marido desta mulher (pater is est quem nuptiae demonstrant), com a inserção de presunções quanto a esta paternidade no art. 1597 do Código Civil. De outra sorte, inexiste presunção em sede de filiação extramatrimonial, situação em que o reconhecimento da paternidade por parte do pai se faz necessária.

Todavia, em razão da evolução da ciência atualmente a questão da paternidade, quanto ao seu aspecto biológico, reúne meios técnicos que permitem aferir com precisão qual a procedência genética de cada pessoa, mormente por meio do exame de DNA. Há ainda que se considerar que as técnicas de inseminação artificial existentes atualmente permitem até mesmo que se questione a maternidade daquela que deu a luz.

Diante desta realidade científica, o Conselho Federal de Medicina (CFM) publicou a Resolução 2.013/13, de 09 de maio de 2.013, tratando da reprodução assistida, revogando a Resolução 1.957/10, sendo certo que a nova redação se deu muito em decorrência do posicionamento do Supremo Tribunal Federal que reconheceu a união homossexual estável (o texto revogado não fazia qualquer menção a orientação sexual ou estado civil).

Ressalta-se que as resoluções do Conselho Federal de Medicina (CFM) não se revestem de força legislativa, vinculando apenas os profissionais da área médica e não a população como um todo. Em outras nações a questão da inseminação artificial é considerada na legislação, como se dá, por exemplo, na França, através da denominada de PMA (procréation médicalement assistée - reprodução medicamente assistida), prevista no Código Civil daquele país (art. 311-19 e 311-20).

Os pontos principais da Resolução 2013/13 estão relacionados à determinação expressa de que as técnicas de reprodução assistida podem beneficiar qualquer pessoa, ainda que solteira ou em relacionamento homoafetivo, conforme dispõe o item II, 2, a fixação da idade das mulheres que poderão receber a inseminação artificial e a quantidade de embriões a serem transferidos ${ }^{432}$ e a fixação de critérios para a gestação em substituição, conhecida como barriga de aluguel.

${ }^{431}$ SZANIAWSKI, Elimar. Limites e possibilidades do direito de redesignação do estado sexual, São Paulo, RT, 1998, p. 140.

${ }^{432}$ Resolução 2013/13: 6 - O número máximo de oócitos e embriões a serem transferidos para a receptora não pode ser superior a quatro. Quanto ao número de embriões a serem transferidos faz-se as seguintes recomendações: a) mulheres com até 35 anos: até 2 embriões; b) mulheres entre 36 e 39 anos: até 3 embriões; c) mulheres entre 40 e 50 anos: até 4 embriões; d) nas situações de doação de óvulos e embriões, considera-se a idade da doadora no momento da coleta dos óvulos. 
Neste último aspecto a Resolução fixa que a doadora temporária de útero há de ser parente daqueles que solicitam a gestação em substituição até o $4^{\circ}$ grau consanguíneo, indicando de maneira incompleta quem seriam estes parentes, em uma situação que traz uma restrição acerca da realização da inseminação artificial nestes casos.

\section{RESOLUÇÃO 2013/13 DO CONSELHO FEDERAL DE MEDICINA}

De forma a suprir a ausência legislativa e estabelecer os parâmetros mínimos de atuação dos profissionais da área médica, o Conselho Federal de Medicina (CFM) estabeleceu, por meio da Resolução 2013/13, alguns parâmetros que devem nortear a reprodução assistida em território nacional. Embora, a resolução não se revista de caráter legislativo ela traz as diretrizes de conduta a serem seguidas pelos médicos que atuam nesta área especifica do conhecimento.

Inicialmente é de se consignar que o elemento que levou à edição da presente resolução, conforme se explicita em seu próprio corpo, foi o posicionamento adotado pelo Supremo Tribunal Federal na ADI 4.277 e ADPF 132 que reconheceu a união homossexual estável como modalidade de entidade familiar, conferindo direitos aos casais estabelecidos entre pessoas do mesmo sexo, publicada no DOU de 05 de maio de $2011^{433}$.

Tal informação é de suma relevância a fim de se entender o contexto social em que se insere a resolução, mormente se considerando que ela vem a revogar o disposto na Resolução CFM n ${ }^{\circ}$ 1.957/10, publicada no D.O.U. de 6 de janeiro de 2011, que era a que tratava da questão da reprodução assistida anteriormente. Ressalta-se que não é comum uma alteração desta natureza num espaço de tempo tão curto, a não ser em casos em que as mudanças sociais clamam por uma pronta adaptação.

Em que pese todo o preconceito que ainda grassa na sociedade brasileira, a qual ao mesmo tempo que se autodeclara liberal e moderna, com inúmeras situações de liberdade de expressão e moral, se mostra altamente retrograda e com conceitos religiosos fixando a conduta da população, o Conselho Federal de Medicina (CFM) tomou uma atitude adequada ao seu tempo e considerou a questão da união homossexual como uma realidade para a análise da questão da reprodução assistida.

Fato é que a infertilidade humana é uma questão de suma relevância na sociedade merecendo, portanto, a devida atenção de todos os órgãos a fim de garantir a dignidade da pessoa humana, preceito fundamental de um Estado Democrático de Direito, neste sentido "[...] os Direitos Fundamentais, devem ser concretizados, para que se tenha realmente a satisfatividade da dignidade da pessoa humana"434. De se

${ }^{433}$ CUNHA, Leandro Reinaldo da. A união homossexual ou homoafetiva e o atual posicionamento do STF sobre o tema (ADI 4277), vol. 8, São Bernardo do Campo: Metodista, 2010. ${ }^{434}$ DOMINGOS, Terezinha de Oliveira. A Capacidade Contributiva Sob O Enfoque Do Capitalismo Humanista. 179 f. Tese - Pontifícia Universidade Católica de São Paulo, São Paulo. 
considerar que o interesse em procriar é inerente à condição humana e a infertilidade atinge a mais diversa gama de pessoas, independentemente de sua orientação sexual ou identidade de gênero.

A infertilidade é condição de saúde, a qual não pode ser olvidada, mormente ao se ter em conta de consideração o fato de que o direito à saúde é garantia constitucional, conforme bem consigna o artigo 196 da Constituição Federal. O direito à saúde, há que se ressaltar, não se restringe ao âmbito no aspecto físico, mas à integridade humana como um todo, abrangendo também o aspecto psicológico ou moral, inserindo-se no contexto dos direitos da personalidade.

O objetivo primordial da reprodução assistida é viabilizar o processo de procriação nas hipóteses em que as pessoas que tencionam ter filhos se veem impedidas de atingir este escopo através dos meios ordinários para tanto, por meio do empenho de técnicas médicas que se fazem presentes, ante ao crescente desenvolvimento científico que reina nesta específica área do conhecimento médico científico.

Alguns pontos consignados no corpo da resolução merecem especial atenção, conforme se passará a expor.

\subsection{Requisitos PESSOAis PARA A PARTICIPAÇÃo EM PROCESSO de REPROdUÇão ASSISTIDA}

A Resolução 2013/13 do Conselho Federal de Medicina (CFM) firma alguns requisitos que entende necessários para que se possa participar do processo de reprodução assistida, com o objetivo de garantir ou ao menos potencializar a possibilidade de que o tratamento se mostre efetivo.

Dentre os requisitos consignados para que se dê a utilização das técnicas de reprodução assistida está a existência de possibilidade efetiva de sucesso e não se incorra em risco grave de saúde para a paciente ou o possível descendente, bem como a idade máxima das candidatas à gestação por reprodução assistida de 50 anos, como consta dos princípios gerais da resolução.

Todavia, ainda que se trate de elementos de ordem clínica, é de se entender que tais parâmetros não podem ser considerados, em sua totalidade, de forma peremptória, vez que eventualmente serão inadequados.

O critério da possibilidade efetiva de sucesso do tratamento para a reprodução assistida se mostra absolutamente pertinente, vez que não se poderia pensar na realização dos procedimentos em casos em que inexiste a real possibilidade de que este venha a se mostrar exitoso, consignando-se ainda que o profissional que agisse desta forma estaria atando de forma ilícita, cabendo até mesmo se questionar a sua responsabilização civil e penal.

O mesmo pode ser asseverado acerca da questão da inexistência de grave risco à saúde tanto da paciente quando da eventual prole, vez que a higidez física

2010. Publicação digital. 
do ser humano é um preceito basilar e norteador de toda a sociedade, bem como do ordenamento jurídico.

De outra feita, contudo, não se reveste de toda a técnica a imposição de um requisito etário no presente caso. $\mathrm{O}$ texto da resolução pugna que a idade máxima para as mulheres que queiram participar do processo de reprodução assistida seja de 50 (cinquenta) anos, firmando um critério inadequado, vez que ao se considerar o estabelecimento da aferição da possibilidade efetiva do tratamento esta questão estaria afastada. A presente fixação etária pode dar ensejo à impetração de mandado de segurança daquelas mulheres que venham a ser diagnosticadas em perfeitas clínicas condições de participar do processo de reprodução assistida com sucesso, mas que já tenham passado pela barreira dos 50 (cinquenta) anos.

Nas regras gerais com relação aos pacientes, a resolução impõe que os pacientes das técnicas de reprodução assistida sejam pessoas capazes e que tenham solicitado a participação neste tipo de procedimento, estando de pleno acordo com a situação e tendo pleno conhecimento acerca do que virá a ocorrer, por meio do termo de consentimento livre e esclarecido que se exige.

Neste aspecto a resolução afasta a possibilidade de extração de material genético post mortem (nos casos em que tal retirada se mostre possível logo após a morte do sujeito), ou mesmo a utilização do material sem a expressa concordância do sujeito.

\subsection{Sexualidade e ReProdução assistida}

Entendeu por bem a Resolução 2013/13 do Conselho Federal de Medicina (CFM) consignar de forma expressa acerca da possibilidade da utilização das técnicas de reprodução assistida em relacionamentos homossexuais e por pessoas solteiras (respeitado o direito da objeção de consciência do médico).

Muito se questionou com relação à possibilidade de se permitir a procriação em casos em que não se configuraria a estrutura da família clássica, constituída pelo casamento, ou mesmo pela outra modalidade de convivência familiar expressamente inscrita no corpo da Constituição Federal de 1988, a união estável, vez que seriam estas as formas naturais de estabelecimento de família e, portanto, de procriação. Evidente que tal posicionamento se mostrava altamente discriminatório e anacrônico, vez que atualmente há um enorme número de situações em que a reprodução se dá independentemente de constituição de convivência entre os genitores. Sobre a temática Maria Berenice Dias ${ }^{435}$ discorre:

Os novos contornos da família estão desafiando a possibilidade de se encontrar uma conceituação única para sua identificação.

${ }^{435}$ DIAS, Maria Berenice. Manual de Direito das Famílias. Editora Revista dos Tribunais. 2011, p. 43. 
É necessário ter uma visão pluralista da família, abrigando os mais diversos arranjos familiares, devendo-se buscar o elemento que permite enlaçar no conceito de entidade familiar todos os relacionamentos que tem origem em um elo de efetividade, independentemente de sua conformação. O desafio dos dias de hoje é achar o toque identificador das estruturas interpessoais que autorize nominá-las como família.

[...] A família é um grupo social fundado essencialmente nos laços de afetividade após o desaparecimento da família patriarcal, que desempenhava funções procriativas, econômicas, religiosas e políticas (grifo do autor).

No que se refere aos casais homossexuais a questão da impossibilidade da procriação está vinculada a uma restrição física, motivo pelo qual as técnicas de reprodução assistida se mostram preponderantes a fim de permitir que estas pessoas vejam garantidos o seu direito de procriar.

A orientação sexual ou a identidade de gênero de uma pessoa não pode e não deve ser estabelecida como parâmetro ou requisito para a concessão de qualquer sorte de direito em um Estado Democrático de Direito, vez que a imposição de restrições desta natureza revela-se como uma clara e absurda ofensa aos direitos da personalidade e ao princípio da dignidade da pessoa humana ${ }^{436}$. Como bem pugna Elimar Szaniawski, o "direito à procriação do ser humano", estabelece-se como uma projeção da personalidade humana, decorrente do direito da personalidade, surgindo daí um direito subjetivo de procriar ${ }^{437}$, desdobramento do direito à parentalidade, não podendo ser restrito sem uma real razão.

No que se refere à questão da pessoa solteira é de se entender que a imposição de qualquer impedimento também haveria de ser considerado discriminatório, vez que ante a secularização do Estado não há mais que prevalecer o entendimento forjado pela Igreja de que caberia às pessoas o dever de casar e procriar, nesta ordem. A legislação pátria não traz qualquer regramento do sentido de possibilidade ou não de gestação, sendo esta situação uma realidade social que não cabe à norma tentar restringir.

\footnotetext{
${ }^{436}$ Ensina Ingo Wolfgang Sarlet [...] a dignidade é algo inerente a essência do ser humano e que o qualifica como tal, sustenta-se que a dignidade da pessoa humana é algo do qual nem este pode livremente dispor, sendo, portanto, irrenunciável, inalienável e intangível. Relembre-se, neste contexto, que todos os seres humanos nascem livres e iguais em dignidade, e é a dignidade de cada pessoa que deve ser objeto do respeito e proteção por parte do Estado e da comunidade. SARLET, Ingo Wolfgang. A Eficácia dos Direitos Fundamentais. Porto Alegre: Livraria do Advogado, 1998, p. 112.

${ }^{437}$ SZANIAWSKI, Elimar. Limites e possibilidades do direito de redesignação do estado sexual, São Paulo, RT, 1998, p. 143.
} 


\subsection{Das Responsabilidades dos estabelecimentos Que EFETIVAM aS TÉCNI- CAS DE REPRODUÇÃO ASSISTIDA}

Outro ponto que merece atenção no corpo da Resolução 2013/13 do Conselho Federal de Medicina (CFM) está relacionado à imposição de procedimentos a serem adorados pelas clínicas ou centros que realizam as técnicas de reprodução assistida, fixando responsabilidade pelos serviços por eles prestados.

Inicialmente há a determinação da responsabilidade das clínicas e centros pelo "controle de doenças infectocontagiosas, coleta, manuseio, conservação, distribuição, transferência e descarte de material biológico humano para a paciente de técnicas de RA". De se evidenciar que a desatenção a estes parâmetros estabelecidos podem ensejar a responsabilização civil da clínica ou centro pelos danos eventualmente causados, sendo possível se consignar a aplicação dos preceitos do Código de Defesa do Consumidor, já que se trata de uma relação de consumo, nos termos da lei.

Neste âmbito é importante se asseverar que a Resolução impõe ainda às clínicas e centros a manutenção de um "registro permanente (obtido por meio de informações observadas ou relatadas por fonte competente) das gestações, nascimentos e malformações de fetos ou recém-nascidos, provenientes das diferentes técnicas de RA aplicadas na unidade em apreço, bem como dos procedimentos laboratoriais na manipulação de gametas e embriões" (item III, 2), bem como "um registro permanente das provas diagnósticas a que é submetido o material biológico humano que será transferido aos pacientes das técnicas de RA, com a finalidade precípua de evitar a transmissão de doenças" (item III, 3), registros estes que haverão de estar disponíveis para fiscalização dos Conselhos Regionais de Medicina.

Verifica-se, portanto, que para que a clínica ou centro venha a atuar na área da reprodução assistida haverá de atender a alguns requisitos básicos a fim de garantir que o serviço prestado tenha uma eficiência e qualidade mínimos.

\section{DA DOAÇÃo DE MATÉRIAL GENÉTICo}

Outra diretriz considerada relevante pelo Conselho Federal de Medicina (CFM) é a relacionada à doação de gametas ou embriões. Inicialmente é de se considerar que a questão da doação de esperma e óvulos não se enquadram no disposto na Lei $\mathrm{n}^{\circ}$ 9.434, de 4 de fevereiro de 1997, que dispõe sobre a remoção de órgãos, tecidos e partes do corpo humano para fins de transplante e tratamento e dá outras providências, como expressamente consta do texto do parágrafo único do art. $1^{\circ} \mathrm{da}$ referida lei.

A resolução estabelece como parâmetros para a doação que esta não tenha caráter lucrativo ou comercial (item IV, 1), a proteção da identidade de doadores/ receptores (item IV, 2 e 4) e o estabelecimento de idade limite para os doadores (item IV, 3). 
A proibição da doação com caráter lucrativo ou comercial converge com a previsão consignada na lei para os casos de doação de órgãos conforme consignado na Lei 9.434/97, vez que o posicionamento adotado em nosso país é de que tais atos devem ser lastreados pelo caráter altruístico.

O critério da limitação etária (35 anos para mulheres e 50 anos para homens) é de fundo técnico, contudo, pode ser questionado vez que eventualmente alguém que não se encontra incluído no parâmetro proposto pode apresentar condições clínicas para a oferta de material genético de qualidade e que poderia ser utilizado em reprodução assistida.

O ponto de maior celeuma está vinculado à questão da proteção da identidade de doadores e receptores, sendo esta a regra, consignando-se como exceção situações especiais em que, por motivação médica, as informações podem ser fornecidas exclusivamente a médicos, resguardadas a identidade civil do doador. A perspectiva do Conselho Federal de Medicina (CFM) é que caso as informações possam ser consideradas relevantes para a saúde pode haver a quebra do sigilo de identidade, motivo pelo qual as "clínicas, centros ou serviços que empregam a doação devem manter, de forma permanente, um registro de dados clínicos de caráter geral, características fenotípicas e uma amostra de material celular dos doadores, de acordo com a legislação vigente".

De se considerar que em situação similar à presente, a legislação pátria assevera que é um direito ter conhecimento à origem biológica, como é o caso da adoção, nos termos do art. 48 do Estatuto da Criança e do Adolescente, que assevera tal prerrogativa ao adotado após completar 18 (dezoito) anos, ainda que tal fato não possa trazer qualquer tipo de consequência no que concerne a aquisição de direitos familiares ou sucessórios.

Evidencia-se assim que tal questão depende necessariamente de regramento legislativo, sendo de se pugnar, de lege ferenda, pela possibilidade de que caso haja interesse seja permitido à pessoa nascida em decorrência de reprodução assistida que ela venha a ter conhecimento do processo de inseminação como um todo, impedindo a existência de qualquer consequência jurídica em decorrência destas informações.

Interessante notar que o Conselho Federal de Medicina (CFM) confere às clínicas e centros a responsabilidade pela escolha dos doadores, cabendo a eles, na medida do possível, buscar um doador que apresente a maior semelhança fenotípica e imunológica possível, bem como a máxima compatibilidade possível com a receptora, sendo certo que é vedada qualquer sorte de seleção genética, salvo no que se refere a alterações genéticas causadoras de doenças, como consignado no item VI, 1 .

Esta última questão, relacionada à seleção genética, se mostra extremamente controversa, gerando enorme celeuma na esfera da bioética e, consequentemente, do biodireito, tema que se mostra absolutamente relevante, mas que não cabe no escopo do presente trabalho. 
Ainda no que concerne à questão dos doadores o Conselho Federal de Medicina (CFM) assevera que "na região de localização da unidade, o registro dos nascimentos evitará que um(a) doador(a) tenha produzido mais que duas gestações de crianças de sexos diferentes, numa área de um milhão de habitantes", com o objetivo de evitar riscos de relacionamento e procriação entre pessoas que tenham tido o mesmo doador, situação em que ensejaria um agravamento do risco de problemas genéticos para a prole deste eventual casal.

\subsection{Do DESTINO DO MATERIAL GENÉTICO NÃO UTILIZADO}

A Resolução 2013/13 do Conselho Federal de Medicina (CFM) consigna que o material genético, sejam espermatozoides, óvulos e embriões ou tecidos gonádicos, podem ser congelados (criopreservação), sendo certo que o "número total de embriões produzidos em laboratório será comunicado aos pacientes, para que decidam quantos embriões serão transferidos a fresco, devendo os excedentes, viáveis, serem criopreservados". No instante em que determinar o congelamento do material genético o doador há de informar, ante a declaração de vontade expressa e por escrito, qual o destino a ser dado a tais embriões "em caso de divórcio, doenças graves ou falecimento de um deles ou de ambos, e quando desejam doá-los".

Esta determinação de que o destino do material criopreservado seja decidido ao se requerer seu congelamento aparenta ser apenas uma precaução do Conselho Federal de Medicina (CFM) para que não se estabeleça maiores celeumas nos casos ali consignados, contudo, é de se entender que nada impede que a manifestação ali apresentada venha a ser objeto de questionamento ou mesmo modificação de vontade.

Ainda no contexto da criopreservação, a presente resolução assevera a possibilidade de descarte dos embriões neste estado, desde que se encontrem armazenados há mais de 5 (cinco) anos, desde que esta seja a vontade dos pacientes, complementando a concepção constante da Lei de Biossegurança, que determina a possibilidade de encaminhamento de tais embriões para pesquisas de célula-tronco após 3 (três) anos de congelamento (art. $5^{\circ}$, II da Lei 11.105/05).

$\mathrm{O}$ descarte de embriões criopreservados é ponto enorme questionamento e que certamente dará ensejo a uma enorme discussão, mormente se considerados os aspectos religiosos que podem ser vinculados ao tema.

\section{GestaÇão em SUbSTituição}

A gestação em substituição ou doação temporária de útero é aquilo que coloquialmente se convencionou denominar de "barriga de aluguel", situação em que não há a possibilidade de que o interessado ou o casal possa gestar o embrião, havendo a necessidade de valer-se de um terceiro para que a gravidez venha a se 
desenvolver.

Esta questão envolve uma série de elementos relevantes a serem considerados, tais como a questão do contrato a ser entabulado entre as partes (sua natureza, licitude e efetividade), a efetivação do registro de nascimento, bem como os direitos e deveres relacionados.

Reiterando-se que nada há expresso na legislação vigente acerca do tema, o posicionamento apresentado pelo Conselho Federal de Medicina (CFM) pode servir como um alicerce inicial para a elaboração de normas que insiram a questão no ordenamento jurídico vigente.

O tema é objeto de atenção do item VII da Resolução 2013/13 do Conselho Federal de Medicina (CFM), que de pronto afirma que esta modalidade de gestação é admissível quando se constate a existência de um problema médico que impeça ou contraindique a gestação por meios ordinários. Esta restrição impede, de plano, a utilização da gestação em substituição por mera vontade ou discricionariedade, restringindo a plena liberdade de contratar decorrente do princípio da autonomia das vontades na esfera contratual, situação esta que não encontra respaldo no corpo da legislação vigente.

O texto da referida resolução impõe ainda que a doadora temporária de útero deve pertencer à família de "um dos parceiros", em expressão inadequada, vez que esta modalidade de reprodução assistida pode ser realizada também por pessoas solteiras. Ainda de se pontuar que a imposição de que a doadora pertença à família não tem respaldo legal, podendo ser questionada judicialmente por quem queira valer-se do método sem envolver familiares.

Quando trata dos familiares que podem integrar a relação de gestação em substituição o Conselho Federal de Medicina (CFM) estabelece vinculação incompleta, vez que ao indicar nominalmente quem seriam as pessoas com legitimidade para figurar nesta doação ignora a possibilidade de alguns parentes dentro do parâmetro estabelecido, olvidando-se da figura da sobrinha ( $3^{\circ}$ grau), e tias-avós e sobrinhas-netas $\left(4^{\circ}\right.$ grau $)$, que seriam pessoas perfeitamente possíveis considerando a realidade social nacional em que tais parentes podem se encontrar em perfeitas condições de gestação, dentro do limite etário de 50 (cinquenta) anos impostos pelo conselho.

A resolução reitera que a gestação em substituição não pode apresentar caráter lucrativo ou comercial, ponto este que também não encontra respaldo no texto da legislação vigente, sendo pertinente se pensar que tal imposição não se bastaria face a previsão constitucional de que ninguém é obrigado senão por disposição de lei, ou mesmo de que tudo o que não for objeto de proibição é permitido. Ressalta-se que o pagamento de todas as despesas médicas pré-natais, bem como a subvenção de meios para a mantença da doadora na constância da gestação não devem ser entendidas como uma forma de pagamento, desnaturando a gratuidade do contrato.

Salta aos olhos o fato da Resolução não considerar a possibilidade de que 
a gestação em substituição se dê em situação em que se tenha que utilizar da inseminação artificial heteróloga, com doação simultânea de óvulo e espermatozoide. Nesta hipótese se teria a existência de um doador de espermatozoide, uma doadora de óvulo, uma terceira pessoa que seria a doadora temporária de útero favorecendo uma pessoa ou casal que não tenha condições de procriar.

O texto da normativa ética do Conselho Federal de Medicina (CFM) consigna ainda que as clínicas devem ter arquivo do termo de consentimento informado dos participantes, "relatório médico com o perfil psicológico, atestando adequação clínica e emocional da doadora temporária do útero, descrição pelo médico assistente, pormenorizada e por escrito, dos aspectos médicos envolvendo todas as circunstâncias da aplicação de uma técnica de RA, com dados de caráter biológico, jurídico, ético e econômico, bem como os resultados obtidos naquela unidade de tratamento com a técnica proposta; - contrato entre os pacientes (pais genéticos) e a doadora temporária do útero (que recebeu o embrião em seu útero e deu à luz), estabelecendo claramente a questão da filiação da criança; - os aspectos biopsicossociais envolvidos no ciclo gravídico-puerperal; - os riscos inerentes à maternidade; - a impossibilidade de interrupção da gravidez após iniciado o processo gestacional, salvo em casos previstos em lei ou autorizados judicialmente; - a garantia de tratamento e acompanhamento médico, inclusive por equipes multidisciplinares, se necessário, à mãe que doará temporariamente o útero, até o puerpério; - a garantia do registro civil da criança pelos pacientes (pais genéticos), devendo esta documentação ser providenciada durante a gravidez; - se a doadora temporária do útero for casada ou viver em união estável, deverá apresentar, por escrito, a aprovação do cônjuge ou companheiro."

Bastante curiosa a determinação da Resolução de que a clínica tenha uma garantia de que a criança venha a ser registrada em nome dos "pais genéticos", que mais tecnicamente haveria de se entender como os contratantes da gestação em substituição, como se apresentará no decorrer no presente trabalho.

Parte do que consta do conteúdo da Resolução está relacionado a aspectos jurídicos que vão muito além do escopo da normativa da entidade de classe médica, vez que atinge aspectos jurídicos de suma relevância.

\subsection{Do CONTRATO de GESTAÇÃo EM SUBSTITUIÇÃo}

De se consignar, inicialmente, que a vinculação entre as partes para a gestação em substituição há de se estabelecer por meio de um contrato vinculando a todos, firmando as obrigações que competirão a cada uma das partes envolvidas na avença entabulada.

Considerando que o texto do Código Civil não traz esta modalidade contratual entre as formas elencadas, caberá a aplicação dos preceitos referentes aos contratos inominados, sendo certo que a única vedação expressa presente na legis- 
lação se refere à herança de pessoa viva (art. 426), fazendo com que não se possa trabalhar, de plano, com a existência de qualquer impeditivo para a realização da doação temporária do útero.

Numa visão preliminar pode-se asseverar que o contrato haveria de ser considerado existente, levando em consideração a escada pontiana dos negócios jurídicos, vez que apresenta manifestação de vontade, idoneidade do objeto e finalidade negocial, o que viabiliza que se passe a aferir o contrato segundo a perspectiva da validade.

Neste âmbito, a legislação determina que o negócio jurídico há de apresentar agente capaz, objeto lícito possível e determinado ou determinável, além de forma não defesa ou prescrita em lei. Evidencia-se a inexistência de qualquer obstáculo quanto a configuração de agente capaz, ante a ausência de restrição de aptidão para quem quer que queira realizar tal avença (com base no que consigna a lei) ou mesmo questões pertinentes à forma, ainda que se sugira que se dê de forma escrita, por meio de escritura pública, sendo certo que toda a questão repousa sobre a figura do objeto, como se passará a analisar.

\subsubsection{Da licitude do objeto do contrato}

A licitude do objeto de qualquer contrato é requisito essencial para a sua validade, entendendo o Código Civil que a desatenção a este aspecto enseja a caracterização da nulidade do negócio jurídico, nos termos do art. 166, II do referido texto legal. Entende-se por lícito o objeto que não se mostre contrário à lei, à moral ou aos bons costumes, apreciação esta que se revela de alta pertinência para a compreensão dos contratos de gestação em substituição.

O ponto inicial para a presente aferição está em se definir qual seria o objeto efetivo do contrato firmado entre aquele que pretende ter um filho e a pessoa que fornecerá o útero para gestação. Possível se consignar que o objeto do contrato seria uma prestação de serviço, uma obrigação de fazer, em que aquela que gestará o embrião terá que praticar este ato em favor de seus contratantes, entregando-lhes o produto desta gestação ao cabo da gravidez.

Se não for este o entendimento, mas sim o de que se trata de uma obrigação de dar, no qual a doadora temporária de útero há de entregar "uma coisa" aos contratantes ao termo do contrato se estará diante de uma situação que ensejará questionamentos de alta incidência ética, com a alegação de que se trataria de um contrato que transferiria um ser humano a outra pessoa, num contexto em que não se admite a comercialização de pessoas.

O elemento objetivo desta avença entabulada pelas partes se mostra importante para a fixação dos desdobramentos deste contrato, vez que em face da relevância de que se reveste trata-sede matéria de ordem pública passível de nulidade, a qual pode ser suscitada por qualquer pessoa, a qualquer tempo, independentemente 
de um prazo específico para tanto.

Nesta perspectiva os desdobramentos de uma eventual configuração de nulidade são severos, ao se considerar que se o referido contrato firmado entre as partes for considerado nulo, o que pode ocorrer independentemente da vontade das partes, haveria de se restabelecer o status quo ante, o que, no presente caso, ensejaria o afastamento do convencionado entre as partes com a obrigatória prevalência do disposto na lei quanto a filiação, fazendo com que a mulher que deu a luz à criança seja considerada sua mãe.

A invalidação do contrato de doação temporária de útero geraria, portanto, sérias consequências, vez que a gestação da doadora se deu exclusivamente com o fulcro de que aquele que com ela contratou viesse a ser considerado como pai da criança gestada, e a atribuição da maternidade à doadora além de atentatória ao princípio da boa-fé contratual seria considerado altamente prejudicial ao interesse da criança, parâmetro elementar quando se trata de criança e adolescente.

De se considerar ainda que, como tal questão seria passível de nulidade, a inexistência de prazo para a sua alegação poderia gerar graves danos de cunho psicológico à criança ou adolescente, podendo desestruturar ou desestabilizar uma estrutura familiar existente e harmônica, até mesmo muitos anos depois de seu nascimento.

\subsection{Da EFICÁCIA do CONTRATO}

Em aspectos práticos, a gestação em substituição apresentará sérios problemas para sua efetivação, vez que exigirá que órgãos públicos venham a reconhecer o contrato firmado pelas partes como elementos válido e eficaz a atribuir a paternidade a quem não gestou ou pariu a criança.

Ordinariamente, nascida a criança, o seu registro de nascimento decorrerá do atestado de nascido vivo que é emitido pelo hospital (situação que não se verifica caso o nascimento não se dê nestes estabelecimentos) no qual consta o nome da pessoa que deu a luz à criança.

Aceitar-se a apresentação de qualquer contrato como documento bastante a se ignorar a informação constante do atestado poderia dar ensejo a uma questão que colocaria em risco a segurança jurídica, vez que tal arranjo poderia fomentar uma série de ilícitos, como a adoção à brasileira. Não se ignora que ainda hoje em nosso país muitas vezes as informações consignadas no registro de nascimento não correspondem a realidade dos fatos, contudo, não se pode permitir que tal situação se perpetue.

Tal questão necessita de uma normatização bastante detalhada a fim de não vir a ser utilizado o contrato da gestação em substituição como um instrumento de ilicitude, questão que retiraria parte da força do instituto que se pretende estabelecer.

De se considerar, neste caso, qual seria a eficácia do presente contrato caso 
a doadora temporária do útero vir a decidir, após o nascimento, não entregar a criança ao contratante. Caberia a propositura de ação de busca e apreensão, ainda que não se trata de uma obrigação de dar coisa certa? Ou seria pertinente se pensar na imposição de cominação pecuniária diária (astreinte) nos termos propostos pelo art. 461 do Código de Processo Civil? Qual seria a pertinência de uma imposição pecuniária a uma pessoa desprovida de recursos financeiros?

É de se entender que a fim de minorar tais riscos que o Conselho Federal de Medicina (CFM) fixou a vinculação de parentesco entre o requerente da doação temporária de útero e a doadora, entretanto, tal relação não é suficiente para impedir que os riscos acima relatados se efetivem.

Questiona-se também se o contrato de gestação em substituição teria o condão de afastar a previsão legislativa, atrelada ao direito de família, que fixa a maternidade àquela mulher que deu a luz à criança, ante a natureza deste ramo do direito civil.

Desta forma, a efetivação do que se busca com a doação temporária de útero depende de um regramento que viabilize a sua eficácia, considerando-se que a questão como se encontra hoje (sem legislação cuidando do tema) se encontra distante do que se tem por necessário para o caso concreto, fazendo existir o risco de que de nada venha a valer todo o trabalho que envolve a gestação em substituição caso não se tenha como efetivar o constante do contrato firmado pelas partes.

\section{Conclusão}

A reprodução humana assistida é tema presente na sociedade atual, sendo parte integrante de questionamento nas mais diversas searas, passando pelo cotidiano das pessoas (através das novelas e filmes) e se instalando no mundo das ciências, com desdobramentos tanto no âmbito da medicina como do Direito, não sendo possível ao ordenamento jurídico simplesmente deixar tal situação ao largo.

A leniência do Estado em cumprir com os deveres que lhe são inerentes, fixando as regras para solucionar as hipóteses que podem gerar conflito social, como é o presente caso, se mostra como uma ofensa aos preceitos fundantes de um Estado Democrático de Direito.

Pouco existe na legislação acerca do tema, não sendo suficiente a tornar o tema objeto de uma estruturação legislativa mínima, havendo apenas parcas previsões legais e regramentos desprovidos de eficácia erga omnes, como é o caso da Resolução 2.013/13 do Conselho Federal de Medicina (CFM). Os elementos constantes da referida resolução são relevantes e servem de parâmetro médico, contudo não expressam soluções para inúmeros aspectos jurídicos que decorrem das técnicas de reprodução assistida existentes.

Há uma série de implicações decorrentes da reprodução humana assistida que dependem de um ordenamento que leve em consideração tanto os aspectos bio- 
lógicos, quanto os afetivos e os sociais, não sendo possível se permitir que a presente lacuna legislativa continue a existir.

Cabe, no presente caso, fixar-se, de lege ferenda, que se estabeleça os parâmetros acerca de quem pode ser doador de material genético e mesmo quem pode vir a ser doador temporário de útero (que se propõe seja qualquer pessoa, independentemente de estado civil, orientação sexual ou identidade de gênero), as considerações sobre o destino dos embriões excedentários (fixando-se a possibilidade de descarte após se verificar a inviabilidade da sua utilização para fins reprodutivos), a reforma das presunções de paternidade vigentes e os limites e consequências dos contratos firmados nesta área (com a prevalência do pacta sunt servanda), a fim de garantir a sua efetivação.

É de se entender, portanto, que urge a elaboração de legislação que estabeleça os parâmetros mínimos para os contratos que versem sobre reprodução assistida, bem como as consequências destes, a fim de conferir segurança jurídica a esta realidade social, de sorte a conferir direitos a quem contrata a reprodução assistida.

\section{REFERÊNCIAS}

CHAVES, Marianna. Parentalidade homoafetiva a procriação natural e medicamente assistida por homossexuais, Diversidade sexual e direito homoafetivo. São Paulo: Revista dos Tribunais, 2011.

CUNHA, Leandro Reinaldo da. Breves considerações sobre a relação entre o direito de família e os direitos humanos, Direitos Humanos - Um enfoque multidisciplinar. São Paulo: Suprema Cultura, 2009.

. A união homossexual ou homoafetiva e o atual posicionamento do STF sobre o tema (ADI 4277), Revista o Curso de Direito da Universidade Metodista de São Paulo - v. 8. São Bernardo do Campo: Metodista. 2010.

CUNHA, Leandro Reinaldo da. DOMINGOS, Terezinha de Oliveira. A nova perspectiva da adoção nacional e o capitalismo humanista, Revista o Curso de Direito da Universidade Metodista de São Paulo - v. 10. São Bernardo do Campo: Metodista. 2012.

DIAS, Maria Berenice. Manual de direito das famílias. 8. ed. rev. e atual. São Paulo: RT, 2011.

DINIZ, Maria Helena, Curso de direito civil brasileiro - Direito de família. 26. ed. São Paulo: Saraiva, 2011.

DOMINGOS, Terezinha de Oliveira. A Capacidade Contributiva Sob O Enfoque Do Capitalismo Humanista. Tese - Pontifícia Universidade Católica de São Paulo, São Paulo. 2010. Publicação digital. 
FIUZA, César. Direito civil - Curso completo. 13. ed. Belo Horizonte: Del Rey, 2009.

GAGLIANO, Pablo Stolze; PAMPLONA FILHO, Rodolfo. Novo curso de direito civil, vol. VI - Direito de família - As famílias em perspectiva constitucional. São Paulo, Saraiva, 2011.

GONÇALVES. Carlos Roberto. Direito civil brasileiro. Volume VI - Direito de família. 7. ed., São Paulo: Saraiva, 2010.

LAGRASTA NETO, Caetano. Direito de família. São Paulo: Malheiros, 2000.

LISBOA, Roberto Senise. Manual de direito civil - Direito de família e sucessões. 5. ed. São Paulo: Saraiva. 2009.

LÔBO, Paulo Luiz Netto. Famílias. 2. ed. São Paulo: Saraiva, 2009.

REALE, Miguel. Função social da família. Disponível em: http://www.miguelreale. com.br/artigos/funsoc.htm. Acessado em: 18..08.2011

SARLET, Ingo Wolfgang. A Eficácia dos Direitos Fundamentais. Porto Alegre: Livraria do Advogado, 1998.

SZANIAWSKI, Elimar. Limites e possibilidades do direito de redesignação do estado sexual. São Paulo, RT, 1998.

VAGGIONE, Juan Marco. La sexualidad em un mundo post secular. El activismo religioso y los derechos sexuales y reproductivos, Derecho a la sexualidad. Buenos Aires: David Grinberg Libros Jurídicos, 2009.

VENOSA. Silvio de Salvo. Direito civil. Volume VI-Direito de família. 11. ed., São Paulo: Atlas, 2011. . Código civil interpretado. 2. ed., São Paulo: Atlas, 2011. 